\title{
Representatividade e liderança feminina nas grandes corporações: uma leitura sob a perspectiva dos movimentos sociais
}

\section{Women's representation and leadership in large corporations: a reading from the perspective of social movements}

\author{
Dirceu Pereira Siqueira ${ }^{l}$ \\ Bruna Furini Lazaretti ${ }^{2}$
}

\section{Resumo:}

Apesar dos grandes avanços conquistados pelos movimentos sociais no decorrer da história, em especial pelos movimentos feministas, a sociedade contemporânea ainda se encontra permeada por desigualdades de gêneros. Nesse sentido, verifica-se que as mulheres ainda são minoria no mercado de trabalho e, especialmente, em cargos de liderança dentro das grandes corporações, sendo que, infelizmente, essa é uma realidade visualizada não apenas no Brasil, mas dentro de um cenário mundial. Faz-se necessário, portanto, analisar o referido problema através de uma perspectiva histórica das construções sociais enraizadas na sociedade, da inserção da mulher no mercado de trabalho e da grande contribuição dos movimentos feministas para este acontecimento, a fim de que se possa chegar a uma conclusão crítica sobre o tema, buscando alternativas à (ainda) contemporânea falta de diversidade de gênero dentro das grandes empresas.

\footnotetext{
${ }^{1}$ Pós-doutor em Direito pela Faculdade de Direito da Universidade de Coimbra (Portugal), Doutor e Mestre em Direito Constitucional pela Instituição Toledo de Ensino - ITE/Bauru, Especialista Lato Sensu em Direito Civil e Processual Civil pelo Centro Universitário de Rio Preto, Pesquisador Bolsista - Modalidade Produtividade em Pesquisa para Doutor - PPD - do Instituto Cesumar de Ciência, Tecnologia e Inovação (ICETI), Professor Permanente do Programa de Mestrado em Direito do Centro Universitário Cesumar (UniCesumar), e nos cursos de graduação em direito da Universidade de Araraquara (UNIARA), do Centro Universitário Unifafibe (UNIFAFIBE) e do Centro Universitário da Fundação Educacional de Barretos (UNIFEB), Professor Convidado do Programa do Programa de Mestrado em "Gestão Estratégica de Empresas - Master Of Science in Administrative Studies (MSAS)" - Disciplina: "Ética e Legislação" University Missouri State - EUA. dpsiqueira@uol.com.br.

${ }^{2}$ Mestranda em Ciências Jurídicas pela UniCesumar (2017). Especialista em Direito Penal e Processual Penal pelo Instituto Paranaense de Ensino (2016). Graduada em Direito pela Universidade Estadual de Maringá (2015)
} 
Palavras-Chave: Mulheres. Representatividade. Liderança. Corporações. Organizações.

\section{Abstract:}

Despite the great advances achieved by social movements in the course of history, especially by feminist movements, contemporary society is still permeated by gender inequalities. In this sense, it can be seen that women are still a minority in the labor market and, especially, in leadership positions within large corporations, and unfortunately this is a reality seen not only in Brazil but within a global scenario. It is necessary, therefore, to analyze this problem through a historical perspective of the social constructions rooted in society, the insertion of women in the labor market and the great contribution of the feminist movements to this event, so that we can reach a critical conclusion on the theme, seeking alternatives to the (still) contemporary lack of gender diversity within large companies.

Keywords: Women. Representativeness. Leadership. Corporations. Organizations.

\section{INTRODUÇÃO}

Apesar dos grandes avanços conquistados pelos movimentos sociais no decorrer da história, em especial pelos movimentos feministas, a sociedade contemporânea ainda se encontra permeada por desigualdades de gêneros.

Nesse sentido, verifica-se que as mulheres ainda são minoria no mercado de trabalho e, especialmente, em cargos de liderança dentro das grandes empresas, sendo que, infelizmente, essa é uma realidade visualizada não apenas no Brasil, mas dentro de um cenário mundial.

Assim, para que seja possível analisar o assunto de maneira crítica, culminando em possíveis soluções para o problema ora apresentado, o artigo será estruturado da seguinte maneira: primeiramente, será realizada uma análise histórica acerca do assunto, explorando a construção das relações de gênero e sua evolução até os dias de hoje; em seguida, será estudado o surgimento do capitalismo, bem como a inserção da mulher no mercado de trabalho dentro desse novo modelo econômico; posteriormente, passa-se à apreciação da 
história dos movimentos feministas ao redor do mundo e, de modo específico, no Brasil, chegando, então, à análise da situação da mulher no atual mercado de trabalho e da liderança feminina nas grandes corporações (também realizando uma análise a respeito de outros países e outra especificamente relacionada ao Brasil).

Portanto, longe da pretensão arrogante de trazer respostas definitivas, o presente artigo se propõe, ao menos, a problematizar o assunto, de tamanha importância na sociedade moderna.

Para o desenvolvimento da pesquisa, foram utilizados os métodos lógico-dedutivo e indutivo argumentativo, através da pesquisa bibliográfica e análise de periódicos, bem como o método histórico, que se concretizou por meio de uma análise crítica dos acontecimentos históricos ocorridos e registrados a respeito da inserção da mulher no mercado de trabalho e da grande contribuição dos movimentos feministas para este acontecimento.

\section{AS RELAÇÕES DE GÊNERO}

\subsection{ESCORÇO HISTÓRICO}

A fim de que se possa compreender melhor a construção das relações de gênero e sua evolução no decorrer da história, é importante que se façam algumas considerações iniciais.

Nesse sentido, destaca-se que as origens mais remotas da existência de categorias jurídicas que se destinavam a tutelar a personalidade humana são encontradas na Grécia e na Roma antigas. $^{3}$

Assim, para o direito romano, a expressão personalidade se restringia aos indivíduos que reunissem três status: o status libertatis; o status civitatis e o status familiae. ${ }^{4}$

O que deve ser notado, no contexto da família romana, é que a mesma se constituía pelo grupo de pessoas subordinadas ao paterfamilias, que era chefe, administrador e sacerdote da família. Somente ele possuía capacidade jurídica plena, sendo que os demais integrantes da família tinham a capacidade de direito reduzida. ${ }^{5}$

\footnotetext{
${ }^{3}$ SZANIAWSKI, Elimar. Direitos de personalidade e sua tutela. $2^{\text {a }}$ ed. rev., atual. e ampl. - São Paulo: Editora Revista dos Tribunais, 2005, p. 23.

${ }^{4}$ SZANIAWSKI, Elimar. Op. Cit., p. 25.

${ }^{5}$ SZANIAWSKI, Op. Cit., p. 27.
} 
Do mesmo modo, na Grécia antiga, Aristóteles descreve que a família (também chamada, nas palavras do filósofo, de "governo doméstico") é constituída pelo senhor e pelo escravo, pelo marido e pela mulher, bem como pelo pai e pelos filhos. ${ }^{6}$ Informa, ainda, que “em todas as espécies, o macho é evidentemente superior à fêmea: a espécie humana não é exceção"?.

O filósofo prossegue, abordando os poderes na família grega, de maneira que, "quanto ao sexo, a diferença é indelével: qualquer que seja a idade da mulher, o homem deve conservar sua superioridade" 8 , bem como que "a força de um homem consiste em se impor, a de uma mulher, em vencer a dificuldade e obedecer"".

É possível verificar, portanto, que a mulher era totalmente submissa ao homem, ao qual cabia o provimento e a administração do lar, sendo que a mulher tinha seu espaço restrito à esfera privada, enquanto que somente o homem (pai, chefe de família) participava como cidadão dotado de personalidade da esfera pública.

Há que se observar que os papéis desempenhados por homens e mulheres são atribuições construídas conforme as necessidades socioeconômicas de cada sociedade, não podendo ser compreendidos como atribuições biológicas. ${ }^{10}$ Isso é comprovado através de relatos de uma sociedade matriarcal, prévia à origem da propriedade privada, na qual:

[...] Mulher detinha o poder e dominava as relações, sendo o homem submisso a ela, uma vez que se acreditava que esta (a mulher) era a única detentora dos meios de reprodução, e por este motivo se acreditava que possuísse algum poder divino e sagrado, merecendo o respeito do homem. ${ }^{11}$

Portanto, a sociedade patriarcal, na qual cabe à mulher as tarefas domésticas e, ao homem, a representação da "fortaleza emocional e física e quem deve apresentar o veredito

\footnotetext{
${ }^{6}$ ARISTÓTELES, A Política. Tradução Roberto Leal Ferreira. São Paulo. Martins Fontes.1991. 1ª Edição, p. 11.

${ }^{7}$ ARISTÓTELES, $O p$. Cit., p. 13.

${ }^{8}$ ARISTÓTELES, Op. Cit., p. 29.

${ }^{9}$ ARISTÓTELES, Op. Cit., p. 31.

${ }^{10}$ GUEDES, Olegna de Souza; PEDRO, Cláudia Bragança. As conquistas do movimento feminista como expressão do protagonismo social das mulheres. In: I Simpósio sobre estudos de gênero e políticas públicas, 1, 2010, Londrina, PR. Anais... Londrina: Universidade Estadual de Londrina, 2010. GT 2. Gênero e movimentos sociais. ISSN 2177-8248, p. 3.

${ }^{11}$ Idem. Ibidem.
} 
final de qualquer decisão a ser tomada"12, surge, apenas, como consequência da propriedade privada e da acumulação de bens, quando o homem "descobre sua colaboração na gestação do filho e sente a necessidade de que as relações se tornem monogâmicas [...], a fim de que o macho pudesse saber quem seria seu herdeiro"13.

Dentro desse contexto, as mulheres começaram a manifestar uma luta pela mudança dos paradigmas sociais que "as enclausuram na esfera privada e numa relação de subserviência em relação aos homens" ${ }^{14}$, quando, então, passam a buscar seus direitos.

\subsection{O SURGIMENTO DO CAPITALISMO E A INSERÇÃO DA MULHER NO MERCADO DE TRABALHO}

A partir do século XIII, com a desestruturação do sistema feudal, a sociedade europeia passou por grandes modificações no setor produtivo e nas relações de trabalho. Nesse período, houve a transferência do centro de vida econômica social e política dos feudos para a cidade.

O período subsequente, compreendido entre os séculos XVI e XVIII e que ficou conhecido como uma fase de "pré-capitalismo", foi marcado pela expansão ultramarina, pela colonização do "novo mundo" (ou seja, dos continentes africano, asiático e americano), pelas políticas mercantilistas (vinculadas à acumulação primitiva de capital, metalismo, balança comercial favorável, etc.), destacando-se Portugal e Espanha como as primeiras potências europeias.

Posteriormente, entre o final do século XVIII e o início do século XIX, já lançadas as bases do capitalismo, teve origem a época conhecida por "capitalismo industrial", caracterizada por inúmeras evoluções (tais quais o desenvolvimento do sistema fabril, a utilização do carvão mineral como fonte de energia para a indústria, a invenção da máquina à vapor), todas elas primordiais à ocorrência da Revolução Industrial na Inglaterra, à qual se seguiram países como França, Alemanha, Estados Unidos e Japão.

A chegada da Revolução Industrial fez com que as indústrias passassem a absorver a mão-de-obra feminina, com o objetivo de baratear os salários, trazendo, de maneira definitiva, a inserção da mulher na produção. ${ }^{15}$

\footnotetext{
${ }^{12}$ Idem. Ibidem.

${ }^{13}$ Idem. Ibidem.

${ }^{14}$ Idem. Ibidem.

${ }^{15}$ HOBSBAWM, E. J. A Era das Revoluções 1789-1848. 18 ed. São Paulo: Editora Paz e Terra, 2004.
} 
Essa tendência se consolidou com a ocorrência da Primeira e Segunda Guerras Mundiais, quando os homens foram para as frentes de batalha e as mulheres passaram a assumir os negócios da família e, consequentemente, a posição de seus pais e maridos no mercado de trabalho. ${ }^{16}$

Também em um contexto pós-guerra as mulheres passaram a trocar o cuidado do lar pelo trabalho fora de casa, eis que muitos dos homens que lutaram por seus países e sobreviveram aos conflitos foram mutilados e, consequentemente, encontravam-se impossibilitados de voltar ao trabalho. ${ }^{17}$

Contudo, as mulheres trabalhavam em jornadas extremamente longas, que ultrapassavam dezesseis horas por dia, e seus salários chegavam a ser até sessenta por cento menor do que dos homens. Com este cenário de exploração e injustiça é que passaram, então, a surgiram manifestações sociais (tal qual o movimento operário), especialmente na Europa e nos Estados Unidos, reivindicando a redução da jornada de trabalho, a equidade entre os salários de homens e mulheres, entre outros. ${ }^{18}$

\section{MOVIMENTOS SOCIAIS}

\subsection{MOVIMENTOS FEMINISTAS}

Os movimentos sociais podem ser entendidos como "uma das possibilidades de defesa e ampliação de direito"19, sendo que, dentro destes, destaca-se o movimento das mulheres.

\footnotetext{
16 ASSIS, Rosiane Hernandes de; ZANUSSO, Renata Cristina Gonçalves de Souza. A inserção da mulher no mercado de trabalho. In: VI Congresso Virtual Brasileiro de Administração, 6, 2009, Brasil. Disponível em: <http://www.convibra.org/2009/artigos/140_0.pdf >. Acesso em: 05/04/2017.

${ }^{17}$ BALTAR, P.; LEONE, E. T. A mulher na recuperação recente do mercado de trabalho brasileiro. Revista brasileira de Estudos Populacionais, São Paulo, v.25, n.2, p. 233-249, jul/dez. 2008. No mesmo sentido: BAYLÃO, André Luís da Silva; SCHETTINO, Elisa Mara Oliveira. A inserção da mulher no mercado de trabalho brasileiro. XI Simpósio de Excelência em Gestão e Tecnologia. SEGeT, 2014. Disponível em: 〈http://www.aedb.br/seget/arquivos/artigos14/20320175.pdf>. Acesso em: 05/04/2017, e PROBST, Elisiana Renata; RAMOS, Paulo. A evolução da mulher no mercado de trabalho. Instituto catarinense de pósgraduação, v.1, n.1, p.1-8, 2013. Disponível em: 〈http://www.posuniasselvi.com.br/artigos/rev02-05.pdf >. Acesso em: 05/04/2017.

18 PROBST, Elisiana Renata; RAMOS, Paulo. A evolução da mulher no mercado de trabalho. Instituto Catarinense de Pós-Graduação, v.1, n.1, p.1-8, 2013. Disponível em: <http://www.posuniasselvi.com.br/artigos/rev02-05.pdf>. Acesso em: 05/04/2017.

19 GUEDES, Olegna de Souza; PEDRO, Cláudia Bragança. As conquistas do movimento feminista como expressão do protagonismo social das mulheres. In: I Simpósio sobre estudos de gênero e políticas públicas,
} 
A luta das mulheres encontra-se focada na libertação de uma cultura e de um senso moral constituído e cimentado, com o passar do tempo, pela cultura machista. As mulheres buscam conquistar seu espaço em relação à igualdade econômica, política, jurídica, bem como na "construção de uma sociedade livre de relações preconceituosas e discriminações" ${ }^{20}$. Tratase, portanto, de uma luta pela igualdade, pela equidade, pela liberdade, pela justiça social e pelo respeito à alteridade, buscando abolir ou, ao menos, transformar profundamente a ordem patriarcal e seu poder regulador. ${ }^{21}$

Veja-se, nesse sentido, que a história das mulheres é permeada por "reivindicações que possuem diversas procedências, mas que convergem na denúncia da exclusão, opressão e discriminação em razão do sexo"22.

O feminismo questiona os dogmas e padrões presentes na sociedade, sendo, portanto, um movimento que, na maioria das vezes, se choca contra a ordem social imposta. Foi através do movimento feminista, em suas primeiras manifestações, que as mulheres conquistaram o direito ao voto, à participação na vida política e o acesso à educação, por exemplo ${ }^{23}$.

Nesse contexto, apesar das divergências dentre os movimentos feministas ao redor do mundo, os mesmos foram os responsáveis por levar à público os problemas diariamente

1, 2010, Londrina, PR. Anais... Londrina: Universidade Estadual de Londrina, 2010. GT 2. Gênero e movimentos sociais. ISSN 2177-8248, p. 5.

${ }^{20}$ Idem. Ibidem.

21 MIRANDA; Cynthia Mara. Os movimentos feministas e a construção de espaços institucionais para a garantia dos direitos das mulheres no Brasil. <http://www.ufrgs.br/nucleomulher/arquivos/os\%20movimentos\%20feminismtas_cyntia.pdf>. Acesso em: 12/04/2017.

${ }^{22}$ ALVES, Aline Cristina. A luta pelos direitos trabalhistas das mulheres no Brasil. Curitiba: Unibrasil, 2014 , p. 34

23 "A chamada primeira onda do feminismo aconteceu a partir das últimas décadas do século XIX, quando as mulheres, primeiro na Inglaterra, organizaram-se para lutar por seus direitos, sendo que o primeiro deles que se popularizou foi o direito ao voto. As sufragetes, como ficaram conhecidas, promoveram grandes manifestações em Londres, foram presas várias vezes, fizeram greves de fome. Em 1913, na famosa corrida de cavalo em Derby, a feminista Emily Davison atirou-se à frente do cavalo do Rei, morrendo. O direito ao voto foi conquistado no Reino Unido em 1918". Além disso, no Brasil, "a primeira onda do feminismo também se manifestou mais publicamente por meio da luta pelo voto. A sufragetes brasileiras foram lideradas por Bertha Lutz, bióloga, cientista de importância, que estudou no exterior e voltou para o Brasil na década de 1910, iniciando a luta pelo voto. Foi uma das fundadoras da Federação Brasileira pelo Progresso Feminino, organização que fez campanha pública pelo voto, tendo inclusive levado, em 1927, um abaixo-assinado ao Senado, pedindo a aprovação do Projeto de Lei, de autoria do Senador Juvenal Larmartine, que dava o direito de voto às mulheres. Este direito foi conquistado em 1932, quando foi promulgado o Novo Código Eleitoral brasileiro". In: PINTO, Céli Regina Jardim. Feminismo, história e poder. Rev. Sociol. Polít., Curitiba, v. 18, n. 36, p. 15-23, jun. 2010 
enfrentados pelas mulheres, desde o início de suas manifestações, a partir do século XIX, até os dias atuais. ${ }^{24}$

Portanto, longe de esgotar o tema, o presente tópico tem a pretensão de trazer uma breve síntese histórica relacionada aos movimentos feministas ao redor do mundo e, especial, no Brasil, para que se possa ter uma compreensão geral a respeito do tema, imprescindível ao prosseguimento do presente artigo.

Assim, cabe destacar que:

O feminismo é tradicionalmente dividido em três ondas, as quais se referem aos movimentos sociais em apoio à mulher que ocorreram em diversos momentos. Essa divisão possibilita estabelecer uma ordem esquemática dos acontecimentos e teorias feministas que surgiram ao longo dos séculos. A primeira onda remete ao feminismo de ordem liberal ou sufragista do século XIX; a segunda onda representa o feminismo das revoluções contraculturais do século $\mathrm{XX}$, mais precisamente das décadas de 1960 e 1970, que se divide em duas correntes principais: o feminismo da diferença e o feminismo radical; e a terceira onda refere-se ao feminismo que desenvolve as diferentes teorias em relação ao gênero. ${ }^{25}$

A primeira onda feminista surgiu em contraponto às ideias iluministas e racionalistas, que excluíam as mulheres do âmbito público. Destaca-se, nessa época, a luta pelos direitos à igualdade entre sexos, independência econômica e participação das mulheres no âmbito público (na política e no Parlamento), onde se tomam as decisões democráticas. Além disso, "as reivindicações do feminismo da primeira onda encontram estreita relação com a teoria dos direitos humanos". ${ }^{26}$

Posteriormente, surgiram, também, as reivindicações trabalhistas das mulheres, que foram apoiadas pelo socialismo de inspiração marxista. De outro norte, verificou-se, também, o surgimento do feminismo anarquista, que buscava a libertação do sistema social instaurado, de preconceitos, tradições e costumes. ${ }^{27}$

\footnotetext{
${ }^{24}$ MIRANDA; Cynthia Mara. Os movimentos feministas e a construção de espaços institucionais para a garantia dos direitos das mulheres no Brasil. Disponível em: <http://www.ufrgs.br/nucleomulher/arquivos/os\%20movimentos\%20feminismtas_cyntia.pdf>. Acesso em: 12/04/2017.

25 ALVES, Aline Cristina. A luta pelos direitos trabalhistas das mulheres no Brasil. Curitiba: Unibrasil, 2014, p. 34.

${ }^{26}$ ALVES, Aline Cristina. Op. Cit., p. 36.

${ }^{27}$ ALVES, Aline Cristina. Op. Cit., p. 38-39.
} 
Já na segunda onda do movimento feminista, que ocorreu aproximadamente entre as décadas de 1960 e 1970, surgiram novos valores sociais e uma nova forma de percepção da mulher. Nessa época, o feminismo "se voltou para o estudo da própria mulher, aprofundandose na questão da mulher como ser autônomo e não um complemento do outro"28.

Por fim, a terceira onda feminista, conhecida como "feminismo pós-moderno", remonta à década de 1980, onde passaram a ser abordados temas como violência doméstica e a proteção da mulher, assédio sexual no ambiente de trabalho, trabalho doméstico, entre outros. $^{29}$

Já no que diz respeito ao movimento feminista no Brasil, cabe destacar, a princípio, a história da colonização de nosso país. Isso porque, "os colonizadores trouxeram consigo, o modelo patriarcal de família e a Igreja Católica como força política e instrumento de controle social” ${ }^{30}$, o que resultou na construção de uma sociedade patriarcal e conservadora.

Assim, na época do Brasil Colônia (1500-1822), vivia-se se uma cultura patriarcal enraizada na repressão às minorias e na desigualdade social. As mulheres não passavam de propriedade de seus pais, maridos, irmãos ou de outro que fosse o chefe da família. ${ }^{31}$

A primeira onda do feminismo no Brasil, assim como na Europa, também teve como objetivo o direito ao voto. A renomada bióloga Bertha Lutz foi a líder do movimento das sufragetes brasileiras e uma das fundadoras da Federação Brasileira pelo Progresso Feminino, em 1919. Foi através dessa organização que o abaixo-assinado pela aprovação do Projeto de Lei que reconhecia o direito ao voto às mulheres foi encaminhado ao Senado no ano de 1927, tendo se tornado Lei no ano de 1932, com o Novo Código Eleitoral brasileiro. ${ }^{32}$

\footnotetext{
${ }^{28}$ ALVES, Aline Cristina. Op. Cit., p. 40.

${ }^{29}$ ALVES, Aline Cristina. Op. Cit., p. 47-48.

30 GUEDES, Olegna de Souza; PEDRO, Cláudia Bragança. As conquistas do movimento feminista como expressão do protagonismo social das mulheres. In: I Simpósio sobre estudos de gênero e políticas públicas, 1, 2010, Londrina, PR. Anais... Londrina: Universidade Estadual de Londrina, 2010. GT 2. Gênero e movimentos sociais. ISSN 2177-8248, p. 6.

31 GUEDES, Olegna de Souza; PEDRO, Cláudia Bragança. As conquistas do movimento feminista como expressão do protagonismo social das mulheres. In: I Simpósio sobre estudos de gênero e políticas públicas, 1, 2010, Londrina, PR. Anais... Londrina: Universidade Estadual de Londrina, 2010. GT 2. Gênero e movimentos sociais. ISSN 2177-8248, p. 6.

${ }^{32}$ PINTO, Céli Regina Jardim. Feminismo, história e poder. Rev. Sociol. Polit., Curitiba, v. 18, n. 36, p. 15-23, jun./2010. Disponível em: $\quad$ http://www.scielo.br/scielo.php?script=sci_arttext\&pid=S010444782010000200003\&lng=en\&nrm=iso >. Acesso em: 19/04/2017. No mesmo sentido, vide BLAY, Eva Alterman. Um caminho ainda em construção: a igualdade de oportunidades para as mulheres. São Paulo: Revista USP, Brasil, n. 49, p. 82-97, mai/2001. ISSN 2316-9036. Disponível em: <http://www.revistas.usp.br/revusp/article/view/32909/35479>. Acesso em: 19/04/2017, e RAMPTON, Martha. The Three waves of feminism. Pacific University Center for Gender Equity, Gender and Sexuality Studies
} 
Já a segunda onda do feminismo em nosso país ocorreu, aproximadamente, entre os anos de 1960 e 1980, sendo que, no ano de 1975, a ONU realizou, no México, a Primeira Conferência Internacional da Mulher e, logo após, patrocinou a semana de debates "O papel e o comportamento da mulher na realidade brasileira". Nesse mesmo ano, houve o lançamento do Movimento Feminino pela Anistia, liderado pela advogada e assistente social Terezinha Zerbini. O auge dessa segunda onda do feminismo brasileiro ocorre com a redemocratização, nos anos de 1980, quando o movimento passa a abranger a luta por temas que vão além da política, tais como violência, sexualidade, direito ao trabalho, igualdade no casamento, direito à saúde da mãe e do bebê, racismo, entre outros. ${ }^{33}$

Por fim, a terceira onda do movimento feminista no Brasil, que vai de 1990 até 2000, buscou a profissionalização e a aprovação de medidas protetoras para que as mulheres pudessem ampliar sua participação política e social. Algumas das demandas do movimento nesse momento é a luta contra a violência (especialmente a violência doméstica), em relação ao qual conquistaram-se inúmeros avanços, tais quais a criação das delegacias especiais da mulher e a Lei Maria da Penha (Lei no 11.340/2006), bem como a descriminalização do aborto, que diz respeito à liberdade sexual da mulher. ${ }^{34}$

\section{A MULHER NO ATUAL MERCADO DE TRABALHO}

\subsection{LIDERANÇA FEMININA NAS GRANDES CORPORAÇÕES}

Apesar dos grandes avanços conquistados pelos movimentos sociais, especialmente pelos movimentos feministas, como visto acima, a realidade ainda se encontra longe de ser

\footnotetext{
Minor, out/2014. Disponível em: <https://www.pacificu.edu/about-us/news-events/four-waves-feminism>. Acesso em: 19/04/2017.

${ }^{33}$ Idem.

${ }^{34}$ PINTO, Céli Regina Jardim. Feminismo, história e poder. Rev. Sociol. Polit., Curitiba, v. 18, n. 36, p. 15-23, jun/2010. Disponível em: <http://www.scielo.br/scielo.php?script=sci_arttext\&pid=S010444782010000200003\&lng=en\&nrm=iso>. Acesso em: 19/04/2017. No mesmo sentido, vide BLAY, Eva Alterman. Um caminho ainda em construção: a igualdade de oportunidades para as mulheres. São Paulo: Revista USP, Brasil, n. 49, p. 82-97, mai/2001. ISSN 2316-9036. Disponível em: <http://www.revistas.usp.br/revusp/article/view/32909/35479>. Acesso em: 19/04/2017, e RAMPTON, Martha. The Three waves of feminism. Pacific University Center for Gender Equity, Gender and Sexuality Studies Minor, out/2014. Disponível em: 〈https://www.pacificu.edu/about-us/news-events/four-waves-feminism>. Acesso em: 19/04/2017.
} 
um cenário ideal em relação à inserção da mulher no mercado de trabalho e, especialmente, em cargos de liderança, como, por exemplo, conselhos corporativos de grandes empresas.

De acordo com recentes pesquisas realizadas nos Estados Unidos, aproximadamente três quartos dos membros dos conselhos corporativos das maiores empresas daquele país são compostos por homens brancos. As mulheres são minoria, ocupando não mais do que dez ou quinze por cento dos cargos de liderança dentro das empresas, sendo que, para mulheres negras, essa porcentagem cai para cerca de três por cento. Em outros países, a realidade se mostra a mesma ou ainda pior, a não ser naqueles países em que há quotas obrigatórias para mulheres dentro das empresas. ${ }^{35}$

Hodiernamente, inúmeras pesquisas abordando a questão das mulheres dentro das grandes corporações têm sido realizadas. Algumas delas informam que, apesar da quantidade de mulheres e minorias nos conselhos corporativos ainda ser pequena, esta quantia tem aumentado com o passar dos anos. Contudo, apesar dos números promissores, o aumento da representação feminina dentro das grandes empresas ainda traz maiores desafios, sendo que alguns dos números mais encorajadores da diversidade dos conselhos corporativos podem esconder tendências menos promissoras (por exemplo, nos Estados Unidos, a Lei SarbanesOxley levou muitas empresas a reduzir o tamanho geral do conselho, o que significa que o mesmo número de mulheres e diretoras pode compor uma maior porcentagem de um conselho agora menor. Além disso, grande parte do aumento de diretores de mulheres e de minoria durante a última década pode refletir que os mesmos indivíduos se sentam em mais conselhos em vez de haver a nomeação de novos indivíduos como diretores. Muitos comentaristas temem que esses "diretores troféus", que podem servir em até sete conselhos, estejam espalhados demais para fornecer uma supervisão adequada. Outra preocupação é que a nomeação de uma ou duas mulheres ou membros de minoria diminuirá a pressão para os esforços contínuos de diversidade). ${ }^{36}$

Outras pesquisas buscaram relacionar a diversidade com o desempenho na empresa, sendo que, embora algumas delas tenham encontrado correlações positivas entre a diversidade

\footnotetext{
35 PACKEL, Amanda K.; RHODE, Deborah. Diversity on Corporate Boards: How Much Difference Does Difference Make? (2014). Delaware Journal of Corporate Law (DJCL), Vol. 39, No. 2 pp. 377-426, 2014. Disponível em: <https://ssrn.com/abstract=1685615> ou <http://dx.doi.org/10.2139/ssrn.1685615>. Acesso em: 09/04/2017.

${ }^{36}$ Idem. Ibidem.
} 
e várias medidas de desempenho da empresa, outras encontraram o oposto ou nenhuma relação significativa. ${ }^{37}$

Nesse sentido, verifica-se que, apesar de grande parte das pesquisas empíricas modernas centrarem-se no gênero, as mesmas trazem resultados inconclusivos e altamente dependentes da metodologia. Isso porque, os resultados mistos refletem diferentes períodos de tempo, países, governos, ambientes econômicos, cultura, tipos de empresas e medidas de diversidade e desempenho financeiro. Existem, ainda, inúmeros outros motivos capazes de explicar a inconclusão desses estudos (tais como deficiências metodológicas que vão desde pequeno tamanho da amostra e observações a curto prazo até a dificuldade de controlar a causalidade reversa e outras variáveis). ${ }^{38}$

O que se pode verificar de maneira cristalina, atualmente, é um consenso na comunidade corporativa a respeito de que a diversidade é um objetivo importante, por proporcionar oportunidades igualitárias a grupos que são historicamente excluídos de posições de poder, sendo que a própria existência da diversidade altera a dinâmica do conselho de uma maneira positiva (por exemplo, a presença de membros visivelmente diversos aumenta a capacidade de um grupo para lidar com o conflito, além de que a diversidade de diretrizes pode transmitir um compromisso com a igualdade de oportunidades, a capacidade de resposta a diversas partes interessadas e uma mensagem geral de liderança progressiva, que pode melhorar a imagem pública da corporação).

Apesar disso, inúmeras são as barreiras existentes a fim de se alcançar a diversidade dentro das grandes empresas. No presente artigo, cita-se, a título exemplificativo, três situações capazes de impossibilitar ou, ao menos, retardar o ingresso de mulheres em de conselhos corporativos.

A primeira delas seria a falta de experiência em liderança, que é uma das razões mais comuns para a sub-representação feminina em conselhos corporativos. Veja-se que a principal rota para cargos de diretoria tem sido através da experiência como CEO em empresas públicas, que é uma das mais importantes experiências profissionais quando se busca um novo diretor. Contudo, as mulheres geralmente ingressam em altos cargos por meio de rotas que não sejam a responsabilidade por lucros e perdas, sendo que, caso os critérios de seleção

\footnotetext{
${ }^{37}$ Idem. Ibidem.

${ }^{38}$ Idem. Ibidem.
} 
não sejam ampliados, seus talentos provavelmente permanecerão sendo subutilizados. Essa perspectiva tem sido paulatinamente modificada, à medida que mais corporações vêm tendo experiências positivas com membros de diretoria de origens variadas. ${ }^{39}$

Um segundo entrave seria o "viés in-group", ou seja, as preferências que os indivíduos sentem por aqueles que são como eles em aspectos importantes, incluindo raça, etnia e gênero. Esse viés mantém as mulheres fora das redes informais de aconselhamento, mentoria e apoio, necessárias para o avanço e através das quais as nomeações são feitas com frequência. Além disso, o favoritismo que ocorre dentro do grupo também é capaz de influenciar as percepções de competência, de maneira que os membros in-groups tendem a atribuir as realizações de outros membros in-groups a características intrínsecas (como inteligência, motivação, empenho, compromisso, etc.), enquanto que atribuem as realizações de membros out-group a fatores externos, tais como sorte ou alguma forma de tratamento especial. É visível, nesse sentido, a presença de estereótipos sobre competência, sobre gênero, entre outros, sendo que, quanto mais subjetivo for o padrão para avaliar as qualificações de possíveis candidatos a cargos dentro das empresas, mais difícil será detectar este "viés ingroup $" 40$.

Outro impedimento seria, ainda, a questão do tokenismo. Essa expressão deriva do termo inglês token, que significa símbolo, e consiste na prática de realizar, publicamente, pequenas concessões a um grupo minoritário (ou seja, criar uma falsa aparência), com a única finalidade de ocultar eventuais acusações de preconceito e/ou discriminação. Em geral, os membros token frequentemente encontram isolamento social, marginalização, pressão para adotar papéis estereotipados, sendo que o tokenismo pode tornar mais difícil que as mulheres e minorias sejam ouvidas igualitariamente a outros membros dentro de um conselho corporativo e pode prejudicar o desempenho dos mesmos. Assim, de acordo com alguns estudos, seria necessária uma "massa crítica" para combater esse fenômeno e efetivar de

39 PACKEL, Amanda K.; RHODE, Deborah. Diversity on Corporate Boards: How Much Difference Does Difference Make? (2014). Delaware Journal of Corporate Law (DJCL), Vol. 39, No. 2 pp. 377-426, 2014. Disponível em: <https://ssrn.com/abstract=1685615> ou <http://dx.doi.org/10.2139/ssrn.1685615>. Acesso em: 09/04/2017.

${ }^{40}$ PACKEL, Amanda K.; RHODE, Deborah. Diversity on Corporate Boards: How Much Difference Does Difference Make? (2014). Delaware Journal of Corporate Law (DJCL), Vol. 39, No. 2 pp. 377-426, 2014. Disponível em: <https://ssrn.com/abstract=1685615> ou <http://dx.doi.org/10.2139/ssrn.1685615>. Acesso em: 09/04/2017. No mesmo sentido, vide METZ, Eduardo Silva. Gestão feminina: a presença das mulheres na liderança de empresas. Ágora: Revista de Divulgação Científica, v. 19, n. 2, p. 169-178, jul./dez. 2014 (ISSNe 2237-9010). 
maneira plena os benefícios da diversidade nos conselhos empresariais. Por exemplo, quando três ou mais mulheres passam a servir juntas em um conselho corporativo, elas passam a se tornar um "estado normal" das coisas, não sendo mais vistas como "outsiders", sendo capazes de influenciar o conteúdo e o processo de discussão do conselho de forma substancial. ${ }^{41}$

Apesar de existirem inúmeras barreiras para se alcançar a diversidade, existem, também, diversas estratégias para mudar, que podem aumentar a diversidade dos conselhos e levar a grandes progressos dentro das próprias corporações. Tais estratégias se dividem em três categorias principais: a) estratégias para os indivíduos; b) estratégias para as instituições e c) estratégias legais.

Em relação à primeira categoria de estratégias, ou seja, aquelas direcionadas aos indivíduos, verifica-se que uma maneira óbvia de expandir o número de mulheres nos conselhos corporativos é aumentar o número de candidatos qualificados, através de programas de mentoria formal, workshops de liderança, consultores de diversidade ou treinadores. Táticas desse tipo podem ajudar os candidatos interessados a definir suas carreiras, refinar seus currículos, desenvolver estratégias de rede e superar barreiras à autopromoção. Inúmeros países, tais como Inglaterra, Canadá, França, Austrália e Estados Unidos têm se utilizado deste método e têm tido sucesso em educar potenciais diretores do sexo feminino, levando os candidatos qualificados para a atenção dos comitês de nomeação de diversos conselhos corporativos. $^{42}$

Já no que concerne às estratégias institucionais, verifica-se que as corporações podem intensificar seus esforços de diversidade, tanto no nível de diretoria como em suas políticas internas, para ajudar a construir um caminho às mulheres qualificadas para as futuras nomeações. Nesse sentido, uma boa opção seria que a empresa definisse suas próprias metas ou requisitos para novas nomeações, a fim de garantir uma massa crítica de mulheres, para posteriormente realizar uma "busca estruturada" (ou seja, a identificação de candidatas mulheres que possam preencher as necessidades funcionais da diretoria). Outras opções para as corporações seriam: a) reduzir a influência dos CEOs no processo seletivo e expandir suas buscas a outras pessoas qualificadas; b) instituir limites de idade e restrições de prazos de

${ }^{41}$ PACKEL, Amanda K.; RHODE, Deborah. Diversity on Corporate Boards: How Much Difference Does Difference Make? (2014). Delaware Journal of Corporate Law (DJCL), Vol. 39, No. 2 pp. 377-426, 2014. Disponível em: 〈https://ssrn.com/abstract=1685615> ou 〈http://dx.doi.org/10.2139/ssrn.1685615>. Acesso em: 09/04/2017.

${ }^{42}$ Idem. Ibidem. 
permanência no cargo, que abrem lugares para que mais mulheres possam ingressar nas empresas; b) tornar mais visível a diversidade dos conselhos (ou sua ausência), comprometendo-se a aumentar a diversidade e a transparência; c) publicar índices de investimento socialmente responsável e responsabilidade social corporativa que incluam medidas de diversidade na liderança. Ainda, seria possível, também, que os investidores dessas corporações agissem, individual e coletivamente, para tornar a diversidade dos conselhos uma prioridade maior nas decisões de investimento (por exemplo, através da criação de fundos para investir em empresas listadas com alto percentual de mulheres em cargos sêniores, inclusive membros de conselhos, entre outras estratégias para recompensar e reformar as empresas com base em seus registros de diversidade). ${ }^{43}$

Por fim, existem, ainda, estratégias legais que podem ser implementadas, sendo que a lei pode desempenhar um papel bastante importante na redução dos obstáculos às mulheres que procuram posições de liderança. Uma proposta bastante comum é exigir que as empresas acima de determinado tamanho divulguem dados sobre recrutamento, retenção e promoção de mulheres, sendo que esse método torna mais fácil para as corporações compararem seu desempenho em relação a outras organizações com posições semelhantes, bem como para as partes interessadas tomarem conta de seus resultados. Além disso, o governo também pode exigir transparência no processo de busca dos conselhos, exigindo que as empresas divulguem se mulheres foram consideradas ou entrevistadas para cargos abertos. Uma terceira abordagem, ainda, seria encorajar as empresas a adotarem uma versão da "Rooney Rule" aplicável ao futebol americano ${ }^{44}$. Ainda, há a possibilidade de aumentar os recursos de aplicação da lei para iniciativas de combate à discriminação ${ }^{45}$, bem como a possibilidade de

43 PACKEL, Amanda K.; RHODE, Deborah. Diversity on Corporate Boards: How Much Difference Does Difference Make? (2014). Delaware Journal of Corporate Law (DJCL), Vol. 39, No. 2 pp. 377-426, 2014. Disponível em: <https://ssrn.com/abstract=1685615> ou <http://dx.doi.org/10.2139/ssrn.1685615>. Acesso em: 09/04/2017.

${ }^{44}$ A NFL exige que as equipes se comprometam a incluir um candidato de minoria entre os finalistas para cada cargo de treinador e gerente geral, bem como que seja realizada uma entrevista no local com esse finalista. Em sete anos desde o início da aplicação da Rooney Rule ao futebol americano, o número de treinadores negros aumentou de seis por cento para vinte e dois por cento.

${ }^{45}$ Isso porque, embora na teoria os indivíduos possam processar por discriminações sexual ou racial em posições de liderança, as dificuldades de produção de prova e a ameaça de "lista negra" tornam tais litígios extremamente raros. No entanto, as agências estaduais e federais de igualdade de oportunidades poderiam ser mais proativas na investigação de organizações com baixo desempenho em questões de gênero e equidade racial. 
estabelecer quotas para membros do conselho de administração das empresas ${ }^{46}$ ou de aplicar uma abordagem de "cumprir ou explicar" em especial na Inglaterra, na Austrália e, em certos contextos, também nos Estados Unidos.

Dentro de todo esse contexto, o que se pode concluir é que a composição (e, em especial, a diversificação) dos conselhos corporativos permanece sendo uma questão significativa na luta por estruturas de liderança mais equitativas, sendo imprescindível que se defenda a diversidade com base em fortes argumentos de equidade e de reputação. $\mathrm{O}$ significativo progresso relacionado à diversidade que as grandes corporações têm alcançado ao longo dos últimos anos evidencia sua capacidade de mudança progressiva, mas não se pode deixar de lado, jamais, que ainda existe muito avanço a ser feito, a fim de que se possa chegar à conselhos corporativos verdadeiramente inclusivos.

\subsection{PESQUISAS REALIZADAS NO BRASIL}

Em nosso país, o Instituto Ethos realiza inúmeras pesquisas relacionadas às grandes empresas e sua responsabilidade social. Nesse sentido, no ano de 2003 o referido órgão realizou uma pesquisa denominada "Perfil Social, Racial e de Gênero das 500 Maiores Empresas do Brasil e Suas Ações Afirmativas" ${ }^{48}$, onde identificou que:

[...] A pirâmide ocupacional nas grandes organizações empresariais é extremamente excludente para as mulheres. Analisando o perfil das maiores empresas do país, a pesquisa revelou que a maioria, $58 \%$, não tem mulheres nos cargos diretivos. $\mathrm{Na}$ média geral da amostra, apenas $9 \%$ dos cargos de direção são ocupados por mulheres, um número muito pouco expressivo diante da participação feminina nessas empresas. A explicação para esse fato não reside no nível de escolaridade das

\footnotetext{
46 A Noruega foi preceptora desta ideia, seguindo-se a ela países como Espanha, Holanda, Bélgica, Itália, Finlândia, França, Inglaterra, Alemanha, Bélgica, Suécia, Emirados Árabes, Índia, entre outros países.

${ }^{47}$ Chamada de "comply or explain", a referida técnica se refere à ideia de que empresas com baixa quantia de mulheres em seus conselhos teriam que explicar o porquê de contratarem um homem para uma vaga em aberto. Pesquisadores sugerem que, ao ser necessário explicar as ações realizadas, a qualidade da tomada de decisões tende a melhorar. Outro viés dessa mesma estratégia seria exigir às empresas que adotem políticas com objetivos mensuráveis para alcançar a diversidade e avaliar os progressos alcançados, ou para explicar por que razão não adotaram tais políticas.

48 INSTITUTO ETHOS (2004). O Compromisso das Empresas com a Valorização da Mulher. São Paulo: Instituto Ethos, 2004, p. 25. Disponível em: <http://www.spm.gov.br/assuntos/poder-e-participacaopolitica/referencias/genero-e-mercado-de-trabalho-pr/o_compromisso_das_empresas_.pdf $>$. Acesso em: 20/03/2017.
} 
brasileiras, mas sim nas barreiras invisíveis para a carreira das mulheres no mundo do trabalho.

Além disso, de acordo com a mesma pesquisa, pouquíssimas organizações (in casu, apenas três por cento das empresas envolvidas no estudo) possuem políticas claras de promoção de equidade de gênero, visando a redução das desigualdades salariais e a capacitação profissional específica para melhorar a qualificação das mulheres.

E, nesse contexto, se as mulheres já se encontram prejudicadas, as desvantagens das mulheres negras dentro das grandes empresas são ainda maiores, sendo que sua participação em cargos de gerência é de apenas um por cento e, nos cargos executivos, é inferior a um por cento.

Entre 2014 e 2016, a pesquisa do Instituto Ethos acerca do "Perfil Social, Racial e de Gênero das 500 Maiores Empresas do Brasil e Suas Ações Afirmativas" foi atualizada ${ }^{49}$. Contudo, os resultados são semelhantes aos dados anteriormente apresentados "ao menos em seus principais aspectos, a começar pela desigualdade entre os sexos e a sub-representação das mulheres, tendo em conta os dados sobre sua presença na sociedade brasileira" ${ }^{\text {" }}$.

Outro ponto que chama atenção em relação a esta última pesquisa é que há um "afunilamento hierárquico" no corpo de funcionários das empresas, com menor inclusão de mulheres à medida que aumentam as atribuições de comando. ${ }^{51}$

Destaca-se a informação disposta na pesquisa de que a ação das empresas para mudar esse cenário ainda não alcança o estágio buscado. Nesse sentido, parte das organizações diz não possuir medidas para incentivar a presença de mulheres no quadro executivo, sendo que os gestores de várias dessas empresas veem como adequada a proporção de mulheres em todos os níveis funcionais (mesmo quando sua presença é, na verdade, praticamente inexistente e inexpressiva). ${ }^{52}$

A pesquisa do Instituto Ethos, então, chega à conclusão de que:

\footnotetext{
${ }^{49}$ INSTITUTO ETHOS E BID (2016). Perfil social, racial e de gênero das 500 maiores empresas do Brasil e suas ações afirmativas. São Paulo: Instituto Ethos, 2016. Disponível em: <http://www3.ethos.org.br/wpcontent/uploads/2016/05/Perfil_Social_Tacial_Genero_500empresas.pdf>. Acesso em: 20/03/2017.

${ }^{50}$ Idem.

${ }^{51}$ INSTITUTO ETHOS E BID (2016). Perfil social, racial e de gênero das 500 maiores empresas do Brasil e suas ações afirmativas. São Paulo: Instituto Ethos, 2016. Disponível em: <http://www3.ethos.org.br/wpcontent/uploads/2016/05/Perfil_Social_Tacial_Genero_500empresas.pdf >. Acesso em: 20/03/2017.

${ }^{52}$ Idem.
} 
[...] Quando observamos as pessoas que trabalham em médias e grandes empresas no Brasil e vemos as posições ocupadas por elas, fica evidente que alguns grupos sociais estão mais bem representados e que as organizações parecem preferir, para os postos de comando, um tipo específico, qual seja: homem branco, em idade adulta, cisgênero, aparentemente heterossexual e sem deficiência visível. Por certo, esse favoritismo não é declarado abertamente, mas isso é o que constatamos quando observamos, por exemplo, diretores e executivos.

Assim, apesar de persistirem grandes desigualdades dentro das empresas brasileiras nos dias atuais, o tema da diversidade tem sido uma preocupação constante dentro das mesmas, e tem acompanhado um movimento progressivo (mesmo que lento), em busca de um ambiente corporativo mais inclusivo e diverso.

Portanto, cabe às empresas o desempenho e a implementação de um plano de ação e a criação de indicadores de processo e resultado, que deve ser monitorado e avaliado continuamente, a fim de que se possa alcançar a diversidade e a inclusão. ${ }^{53}$

Finalmente, considerando o forte poder de influência que as grandes empresas possuem, cabe a elas dar visibilidade às suas ações, sendo que, assim o fazendo, certamente contribuirão na formação de uma opinião pública favorável ao tema, chamando outras empresas a buscar a igualdade de oportunidades no universo corporativo. ${ }^{54}$

\section{CONCLUSÃO}

No presente trabalho, partiu-se da análise histórica das relações de gênero, delineando as origens mais remotas da sociedade patriarcal, que surgiu como consequência da propriedade privada e da acumulação de bens, quando o homem, então, descobriu sua colaboração na gestação do filho e sentiu a necessidade de que as relações pessoais se tornassem monogâmicas, de forma que o macho pudesse saber quem seria seu herdeiro.

Posteriormente, abordou-se o surgimento do capitalismo, que ocorreu com a desestruturação do sistema feudal e a grande mudança ocorrida no setor produtivo e nas relações de trabalho à época, bem como a gradativa inserção da mulher no mercado de

${ }^{53}$ INSTITUTO ETHOS E BID (2016). Perfil social, racial e de gênero das 500 maiores empresas do Brasil e suas ações afirmativas. São Paulo: Instituto Ethos, 2016. Disponível em: <http://www3.ethos.org.br/wpcontent/uploads/2016/05/Perfil_Social_Tacial_Genero_500empresas.pdf $>$. Acesso em: 20/03/2017.

${ }^{54}$ INSTITUTO ETHOS E BID (2016). Perfil social, racial e de gênero das $\mathbf{5 0 0}$ maiores empresas do Brasil e suas ações afirmativas. São Paulo: Instituto Ethos, 2016. Disponível em: <http://www3.ethos.org.br/wpcontent/uploads/2016/05/Perfil_Social_Tacial_Genero_500empresas.pdf >. Acesso em: 20/03/2017. 
trabalho, em especial a partir da revolução industrial e das grandes guerras mundiais, quando, então, os homens passaram a ir para as frentes de batalha e as mulheres começaram a assumir os negócios da família e a posição de seus pais e maridos no mercado de trabalho.

A partir disso, verificou-se que, naquele momento histórico, as mulheres trabalhavam em jornadas extremamente longas e que seus salários chegavam a ser até sessenta por cento menor do que os dos homens. Foi nesse contexto social que passaram, então, a surgir manifestações sociais reivindicando melhoras nas condições de trabalho e nos salários das mulheres, bem como igualdade entre homens e mulheres.

Assim, passou-se à análise dos movimentos sociais, em especial os movimentos feministas, que, desde meados do século XIX, passaram a levar a público os problemas diariamente enfrentados pelas mulheres, buscando uma quebra de paradigmas e uma mudança nas estruturas sociais patriarcais, a fim de as mulheres pudessem conquistar seu próprio espaço dentro da sociedade.

Apesar das inúmeras conquistas alcançadas pelas mulheres e pelos movimentos feministas no decorrer da história, o artigo atenta para o fato de que, até os dias de hoje, a realidade ainda se encontra longe de ser um cenário ideal em relação à inserção da mulher no mercado de trabalho e, especialmente, em cargos de liderança, como, por exemplo, conselhos corporativos de grandes empresas.

Verifica-se, então, que, atualmente, há um consenso na comunidade corporativa a respeito de que a diversidade é um importante objetivo a ser alcançado, por proporcionar oportunidades igualitárias a grupos que são historicamente excluídos de posições de poder (como, por exemplo, as mulheres), sendo que a própria existência da diversidade altera a dinâmica dos conselhos corporativos de uma maneira positiva.

Contudo, inúmeras são as barreiras para se alcançar uma maior inclusão e diversidade dentro das empresas e, em especial, dentro dos conselhos corporativos das grandes companhias. Dentre elas, o artigo cita três situações capazes de impossibilitar ou, ao menos, retardar o ingresso de mulheres em posições de liderança: a) a falta de experiência em liderança; b) o "viés in-group", ou seja, as preferências que os indivíduos sentem por aqueles que são como eles em aspectos importantes, incluindo raça, etnia e gênero; e c) a questão do tokenismo, que consiste na prática de realizar, publicamente, pequenas concessões a um grupo 
minoritário, criando uma falsa aparência, com a única finalidade de ocultar eventuais acusações de preconceito e/ou discriminação.

Por fim, foram apresentadas algumas das possíveis estratégias para que seja possível uma inversão de paradigmas, resultando em uma maior participação feminina no mercado de trabalho e dentro de conselhos corporativos de grandes empresas.

Nesse contexto, haveriam estratégias passíveis de serem adotadas pelos próprios indivíduos interessados nesse tipo de cargo, tais como aumentar o número de candidatos qualificados, através de programas de mentoria formal, workshops de liderança, consultores de diversidade ou treinadores.

Ainda, haveriam estratégias a serem adotadas pelas próprias instituições, como, por exemplo, intensificação dos esforços de diversidade pela companhia; definição de metas ou requisitos para novas nomeações (a fim de garantir uma massa crítica de mulheres); realização de uma "busca estruturada"; redução da influência dos CEOs no processo seletivo; expansão de busca por outras pessoas qualificadas às vagas disponíveis, possibilitação de maior visibilidade da diversidade nos conselhos; publicação de índices de investimento socialmente responsável e responsabilidade social que incluam medidas de diversidade na liderança, entre outras.

Por fim, haveriam estratégias legais aplicáveis para que seja possível garantir uma maior diversidade dentro das empresas, tais como exigir a divulgação de dados e a transparência no processo de busca de novos membros para os conselhos corporativos; aplicar uma versão da "Rooney Rule", relacionada ao futebol americano, às empresas; aumentar os recursos de aplicação da lei para iniciativas de combate à discriminação; estabelecer quotas para membros do conselho administrativo das empresas; ou, ainda, aplicar uma abordagem de “cumprir ou explicar".

Após toda a análise realizada, chegou-se à exposição de dados coletados através de pesquisas realizadas no Brasil, nos últimos anos, acerca da participação das mulheres dentro das maiores empresas no país, que mostram a atual realidade e a dimensão do problema que enfrentamos, bem como o quanto ainda há para mudar.

Por meio da presente pesquisa, longe da pretensão de trazer respostas definitivas, buscou-se a problematizar o assunto, de tamanha importância na sociedade moderna. Em conclusão, verificou-se que a composição (e, em especial, a diversificação) dos conselhos 
corporativos permanece sendo uma questão significativa na luta por estruturas de liderança mais equitativas, sendo imprescindível que se defenda a diversidade com base em fortes argumentos de equidade. O significativo progresso relacionado à diversidade que as grandes corporações têm alcançado ao longo dos últimos anos evidencia sua capacidade de mudança progressiva, mas não se pode deixar de lado, jamais, que ainda existe muito avanço a ser feito, a fim de que se possa chegar a conselhos corporativos verdadeiramente inclusivos.

\section{REFERÊECIAS:}

ALVES, Aline Cristina. A luta pelos direitos trabalhistas das mulheres no Brasil. Curitiba: Unibrasil, 2014.

ARISTÓTELES, A Política. Tradução Roberto Leal Ferreira. São Paulo. Martins Fontes.1991. $1^{\text {a }}$. Edição.

ASSIS, Rosiane Hernandes de; ZANUSSO, Renata Cristina Gonçalves de Souza. A inserção da mulher no mercado de trabalho. In: VI Congresso Virtual Brasileiro de Administração, 6, 2009, Brasil. Disponível em: 〈http://www.convibra.org/2009/artigos/140_0.pdf>.

BALTAR, P.; LEONE, E. T. A mulher na recuperação recente do mercado de trabalho brasileiro. Revista brasileira de Estudos Populacionais, São Paulo, v.25, n.2, p. 233-249, jul/dez. 2008.

BAYLÃO, André Luís da Silva; SCHETTINO, Elisa Mara Oliveira. A inserção da mulher no mercado de trabalho brasileiro. XI Simpósio de Excelência em Gestão e Tecnologia. SEGeT, 2014. Disponível em: 〈http://www.aedb.br/seget/arquivos/artigos14/20320175.pdf>.

BLAY, Eva Alterman. Um caminho ainda em construção: a igualdade de oportunidades para as mulheres. São Paulo: Revista USP, Brasil, n. 49, p. 82-97, mai/2001. ISSN 2316-9036. Disponível em: 〈http://www.revistas.usp.br/revusp/article/view/32909/35479>. 
GUEDES, Olegna de Souza; PEDRO, Cláudia Bragança. As conquistas do movimento feminista como expressão do protagonismo social das mulheres. In: I Simpósio sobre estudos de gênero e políticas públicas, 1, 2010, Londrina, PR. Anais... Londrina: Universidade Estadual de Londrina, 2010. GT 2. Gênero e movimentos sociais. ISSN 21778248.

HOBSBAWM, E. J. A Era das Revoluções 1789-1848. 18 ed. São Paulo: Editora Paz e Terra, 2004.

INSTITUTO ETHOS (2004). O Compromisso das Empresas com a Valorização da Mulher. São Paulo: Instituto Ethos, 2004. Disponível em: $<$ http://www.spm.gov.br/assuntos/poder-e-participacao-politica/referencias/genero-emercado-de-trabalho-pr/o_compromisso_das_empresas_.pdf>.

INSTITUTO ETHOS E ASSOCIAÇÃO MOVIMENTO MULHER 360 (2015). Indicadores Ethos - Guia Temático: Promoção da Equidade de Gênero. São Paulo: Instituto Ethos, 2015. Disponível em: <http://www3.ethos.org.br/wp-content/uploads/2015/09/IndicadoresEthos-MM360_Genero_FINAL.pdf>.

INSTITUTO ETHOS E BID (2016). Perfil social, racial e de gênero das 500 maiores empresas do Brasil e suas ações afirmativas. São Paulo: Instituto Ethos, 2016. Disponível em: $<$ http://www3.ethos.org.br/wpcontent/uploads/2016/05/Perfil_Social_Tacial_Genero_500empresas.pdf>.

INSTITUTO ETHOS E CEERT (2016). Indicadores Ethos para Promoção de Equidade Racial. São Paulo: Instituto Ethos, 06/12/2016. Disponível em: $<$ http://www3.ethos.org.br/categoria/publicacoes/>. 
METZ, Eduardo Silva. Gestão feminina: a presença das mulheres na liderança de empresas. Ágora: Revista de Divulgação Científica, v. 19, n. 2, p. 169-178, jul./dez. 2014 (ISSNe 2237-9010).

MIRANDA; Cynthia Mara. Os movimentos feministas e a construção de espaços institucionais para a garantia dos direitos das mulheres no Brasil. Disponível em: <http://www.ufrgs.br/nucleomulher/arquivos/os\%20movimentos\%20feminismtas_cyntia.pdf>

PACKEL, Amanda K.; RHODE, Deborah. Diversity on Corporate Boards: How Much Difference Does Difference Make? (2014). Delaware Journal of Corporate Law (DJCL), Vol. 39, No. 2 pp. 377-426, 2014. Disponível em: <https://ssrn.com/abstract=1685615> ou <http://dx.doi.org/10.2139/ssrn.1685615>.

PINTO, Céli Regina Jardim. Feminismo, história e poder. Rev. Sociol. Polít., Curitiba, v. 18, n. 36, p. 15-23, jun. 2010.

PROBST, Elisiana Renata; RAMOS, Paulo. A evolução da mulher no mercado de trabalho. Instituto Catarinense de Pós-Graduação, v.1, n.1, p.1-8, 2013. Disponível em: 〈http://www.posuniasselvi.com.br/artigos/rev02-05.pdf> .

RAMPTON, Martha. The Three waves of feminism. Pacific University Center for Gender Equity, Gender and Sexuality Studies Minor, out/2014. Disponível em: <https://www.pacificu.edu/about-us/news-events/four-waves-feminism>.

SZANIAWSKI, Elimar. Direitos de personalidade e sua tutela. $2^{\text {a }}$ ed. rev., atual. e ampl. São Paulo: Editora Revista dos Tribunais, 2005.

Recebido em: 15 de maio de 2017.

Aceito em : 27 de maio de 2017. 